\title{
Call for Papers: Special Issue of Earth, Planets and Space (EPS) "International Geomagnetic Reference Field-the eleventh generation"
}

This special issue of Earth, Planets and Space will be devoted to modelling the Earth's magnetic field, in particular, to the construction of the 11th generation of the International Geomagnetic Reference Field. The IGRF is an internationally-agreed reference model of the Earth's magnetic field produced under the auspices of the International Association of Geomagnetism and Aeronomy. IGRF-11 is the latest update of this well-known model which is used each year by many thousands of users for both industrial and scientific purposes. The derivation of IGRF-11 from satellite and observatory magnetic data, as well as related modelling issues will be the focus of this special issue.

Contributions will include descriptions of the candidate models combined to produce the IGRF-11, details of the evaluation of the candidate models, and a description of the IGRF-11 model itself. In addition, other general contributions related to modelling Earth's internal magnetic field and predicting its future evolution are encouraged.

All submitted papers go through a peer review process, wherein experts review, recommend, or reject the paper for publishing. EPS accepts manuscripts of original research contributions only; so-called "review papers" are not accepted. Submitted papers should not have been previously published nor be currently under consideration for publication elsewhere. Papers must be submitted to the EPS editorial office. Electronic submissions by e-mail to eps@terrapub.co.jp are encouraged, but authors who meet any difficulties with electronic submissions could submit a hard copy by post. For details, please visit the following web page:

http://www.terrapub.co.jp/journals/EPS, and click on "Information for Contributors".

The cover letter should mention "Submitted to the Special Issue: International Geomagnetic Reference Field-the eleventh generation". After papers are accepted, the authors will receive instructions for the final manuscript from the editorial office. The deadline for manuscript submissions is 30th November 2009. This special issue will hopefully be published early in 2010 .

For more information on this special issue, please contact one of the guest editors; questions on manuscript preparation should be addressed to the EPS editorial office.

Guest Editors (chair and co-chair IAGA Working Group V-MOD): Stefan Maus, NOAA, Boulder, USA, E-mail: Stefan.Maus@noaa.gov

Christopher Finlay, ETH Zurich, Switzerland, E-mail: cfinlay@erdw.ethz.ch 